\title{
The Effects of Microchannel Geometry on Phase Transition for Two Phase Flow in Microchannel Heat Sinks
}

\author{
Batan Le, Vanmanh Nguyen, and Thanhtrung Dang \\ Department of Thermal Engineering, Ho Chi Minh City University of Technology and Education, Vietnam \\ Email: trungdang@hcmute.edu.vn
}

\begin{abstract}
The effects of microchannel geometry on the phase transition between liquid and vapour for the two phase flow were investigated both numerically and experimentally. In the study the rounded edge rectangular microchannel heat sink was found to have the phase transition earlier than the rectangular one in both numerical simulation and experimental data by about 1.5 seconds. The outlet temperature and vapour quality of the rounded edge rectangular microchannel heat sink was higher than those obtained from the rectangular microchannel heat sink. Also, the phase transition curves achieved in the evaporation were parabolic in shape. The output vapour temperature achieved a steady state with the maximum value at around 2 minutes, 30 seconds. In addition the numerical results matched well with the experimental data. These numerical results have not yet been seen in literature reviews.
\end{abstract}

Keywords: Microchannel, two phases, temperature, numerical simulation, experiment.

\section{Introduction}

In recent years the heat transfer behaviour of the two phase flow in microchannels has become an interesting topic. Regarding the microchannel heat transfer fields, Yun et al. [1] investigated in the boiling heat transfer coefficients and the two-phase pressure drops of rectangular microchannels. The microchannels have a hydraulic diameter of 1.36 and $1.44 \mathrm{~mm}$. R410A was used as the working fluid and the heat flux obtained was from 10 to $20 \mathrm{~kW} / \mathrm{m} 2$. The results showed that the boiling heat transfer coefficients in the microchannels were much higher than those in single tubes under similar test conditions. In addition, they also showed that the pressure drop accelerated with the increasing mass flux at a constant saturation temperature. Also in addition, the pressure drop decreased with an increasing saturation temperature at a given mass flux, Schilder et al. [2] studied the pressure drop and the convective heat transfer characteristics in a circular tube with a diameter of $600 \mu \mathrm{m}$ and with the working fluid being ethanol. The experiments were carried out for both the two phase flow and single phase flow. The results showed that the mean pressure drop for two phase flow was about three times higher than that for the single phase flow. The Nusselt number for the two phase flow was not dependent on the heat flux and increased with raising the mass flux. The alternating slanted passage in the channel wall as a secondary flow was investigated by Kuppusamy et al. [3]. The results showed that when comparing the alternating slanted passage microchannel heat sink with the conventional one the overall performance of the microchannel heat sink with alternating slanted passage increased by $146 \%$ and the thermal resistance reduced to $76.8 \%$. Ergu et al. [4] studied the pressure drop and local mass transfer of the rectangular microchannel with a hydraulic diameter of $208 \mu \mathrm{m}$. The microchannels have a width of $3.70 \mathrm{~mm}$, a height of $0.107 \mathrm{~mm}$ and a length of $35 \mathrm{~mm}$. Distilled water was used to measure the pressure drop and was also used as the working fluid. Reynolds numbers were in the range of 100-845. A chemical solution was used for measuring the mass transfer and was also used as a working fluid. Reynolds numbers were in the range of 18-552. The results showed that the experimental friction factors are slightly higher than those of the theoretical correlations. Here they observed that the pressure drop increased in line with the Reynolds number.

Singh et al. [5] focused on the impact of the aspect ratio on the overall pressure drop involving water boiling in the microchannels for the two phase flow. In this paper rectangular microchannels were fabricated with varying aspect ratios (width to depth) but the hydraulic diameter was not changed and 
had a value of $142 \pm 2 \mu \mathrm{m}$. In this paper, the working fluid was observed as water. The results showed that the pressure drop had a minimum value at an aspect ratio of about 1.6. Serizawa et al. [6] observed several types of flow such as a dispersed bubbly flow, a gas slug flow, a liquid ring flow, a liquid lump flow, a skewed barbecue shaped flow, an annular flow, a frothy or wispy annular flow, a rivulet flow, and a flow of liquid droplets. In this study the moisture in the air and the steam were used as the working fluid. Megahed [7] investigated the heat transfer and pressure drop characteristics of a cross linked microchannel heat sink for the two phase flow at both low mass fluxes and high heat fluxes. There are 45 straight rectangular microchannels with a dimension of $\mathrm{W}=300 \mu \mathrm{m}, \mathrm{H}=120 \mu \mathrm{m}$ and with the working fluid at FC-72. The results illustrated the heat transfer performance of the oblique-finned microchannels was significantly better than its straight-finned counterpart. Augmenting the heat transfer coefficient happened 1.2 and 6.2 times. The two phase pressure drop in the oblique-finned microchannels was consistently higher than the straight-finned microchannels. They also presented three cross links with a microchannel width of 500um. The experiments were carried out at a range of heat flux from 7.2 to $104.2 \mathrm{~kW} / \mathrm{m} 2$ and with a mass flux from 99 to $290 \mathrm{~kg} / \mathrm{ms}$ and an exit vapour quality ranging from 0.01 to 0.71 . The results showed that the two-phase pressure drop in the cross linked microchannel heat sink strongly increased with an exit quality less than 0.3 and also increased 1.6 twice compared to the straight one. At a constant mass flux the boiling heat transfer coefficient increased with the increasing exit quality. Lee et al. [8] focused on high heat flux microchannel heat sink in refrigeration applications for the two phase flow. A microchannel evaporator was considered in a refrigeration cycle. The rectangular microchannels have the width of $231 \mu \mathrm{m}$ and the depth of $713 \mu \mathrm{m}$. The experiments were carried out with the working fluid at R134a and with the conditions as follows: a mass velocity of $\mathrm{G}=127-654 \mathrm{~kg} / \mathrm{m} 2 \mathrm{~s}$, an inlet quality of xe, in $=0.001-0.25$, an outlet quality of xe,out $=0.49$, a heat flux of q" $=31.938 \mathrm{~W} / \mathrm{cm} 2$, and an inlet pressure of Pin $=1.44-6.60$ bar. The results indicated that the total pressure drop generally increased with an increasing mass velocity and/or heat flux. Three types of inlets/outlets were studied by Wang et al. [9] to find out the effects of inlet/outlet configurations on the flow of boiling instabilities in parallel microchannels. For Type-A the flow enters and exits from channels with restriction. For Type-B the flow enters and exits from microchannels freely without any restriction. For Type-C the flow enters the channels with restriction but exits the channels without restriction. The parallel microchannels have the length of $30 \mathrm{~mm}$ and a hydraulic diameter of $186 \mu \mathrm{m}$. The results showed that configuration $\mathrm{C}$ is the most suitable for microchannel applications with a high heat flux.

A silicon microchannel heat sink was designed by Megahed and Hassan [10]. This research was focused on pressure drops. The microchannels were in a rectangular shape having a depth of 276um, a width of $225 \mathrm{\mu m}$, and a length of $16 \mathrm{~mm}$. Experiments were carried out with the working fluid at FC-72 with these conditions: the ranges of mass fluxes were from 341 to $531 \mathrm{~kg} / \mathrm{m} 2 \mathrm{~s}$ and the heat fluxes were from 60.4 to $130.6 \mathrm{~kW} / \mathrm{m} 2$. The results here showed that the two phase pressure drop strongly depends on the mass flux and increases almost in line with an increasing exit quality at a constant mass flux. Three dimensional wavy rectangular microchannels were tested by Sui et al. [11] with different wavy magnitudes. They also compared the heat transfer performance of the wavy microchannels with straight microchannels. The results showed that wavy microchannels have higher heat transfer performance than those obtained from the straight microchannels. The V-shaped micro evaporator was designed by Tsukamoto and Imai [12]. The results told us that it could achieve $125 \mathrm{~W} / \mathrm{cm} 2$ for a water inlet temperature of $900^{\circ} \mathrm{C}$ and a flow rate of $1.0 \mathrm{~mL} / \mathrm{min}$. The measured pressure drop was less than 1000 $\mathrm{Pa}$.

Based on the above literature reviews the effects of microchannel geometry on phase transition for the two phase flow have not yet been studied by numerical simulation. It is important to clearly understand the effects of microchannel geometry on the phase transition for two phase flow in order to get higher performance from microchannel heat sinks both numerically and experimentally. For the present study two microchannel heat sinks with different channel shapes (including rectangle and rounded edge rectangle shapes) will be discussed.

\section{Methodology}

\section{$2.1 \quad$ Structural Design}


The two typical microchannel heat sinks have the same total dimensions. However, the two heat sinks have different shapes of microchannels. The cross section areas of microchannels are equal $(0.15 \mathrm{~mm} 2)$. This implies that the average velocity in the channels is also the same, as illustrated in Fig. 1. The heat sink consists of two manifolds and microchannels with all microchannels being connected by manifolds. At the beginning the water travels from the inlet manifold through microchannels. After that it goes out of the microchannel heat sink via the outlet manifold. During the journey a heat energy (supplied by a heater at the bottom of an Aluminium substrate during testing) was transferred to the water through microchannels. As a result the amount of heat was dissipated by water.

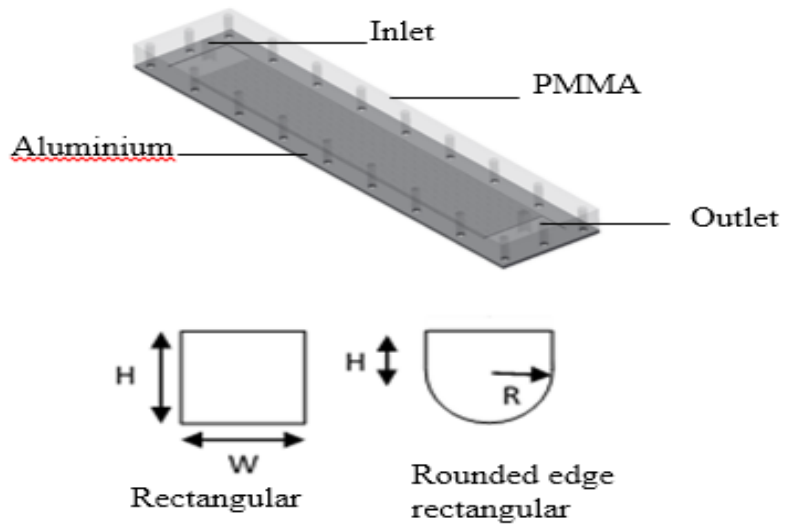

Figure 1. A typical microchannel heat sink and two different cross sections of microchannels

For each heat sink an Aluminium substrate (measuring $152 \mathrm{~mm} \times 31.5 \mathrm{~mm} \times 1.2 \mathrm{~mm}$ ) was used as a fixed substrate for designing with a thermal conductivity of $237 \mathrm{~W} /(\mathrm{mK})$, a density of $2,700 \mathrm{~kg} / \mathrm{m} 3$, and specific heat maintained at a constant pressure of $904 \mathrm{~J} /(\mathrm{kgK})$. Each tested microchannel heat sink contains 25 microchannels with the length of each microchannel at $120 \mathrm{~mm}$. The manifolds of the heat sinks have a rectangular cross-section with a width of $10 \mathrm{~mm}$, a length of $19.5 \mathrm{~mm}$, and a depth of 0.5 $\mathrm{mm}$. The thickness of the substrate is $1.2 \mathrm{~mm}$. To seal the microchannels, a layer of PMMA (Polymethyl methacrylate) was bonded on the top side of the substrate. The PMMA has a thermal conductivity of $0.19 \mathrm{~W} /(\mathrm{mK})$ and a density of $1,420 \mathrm{~kg} / \mathrm{m} 3$. Fig. 2 shows the dimensions of microchannel heat sinks. Table 1 presents the summary of microchannel dimensions for a different cross section.
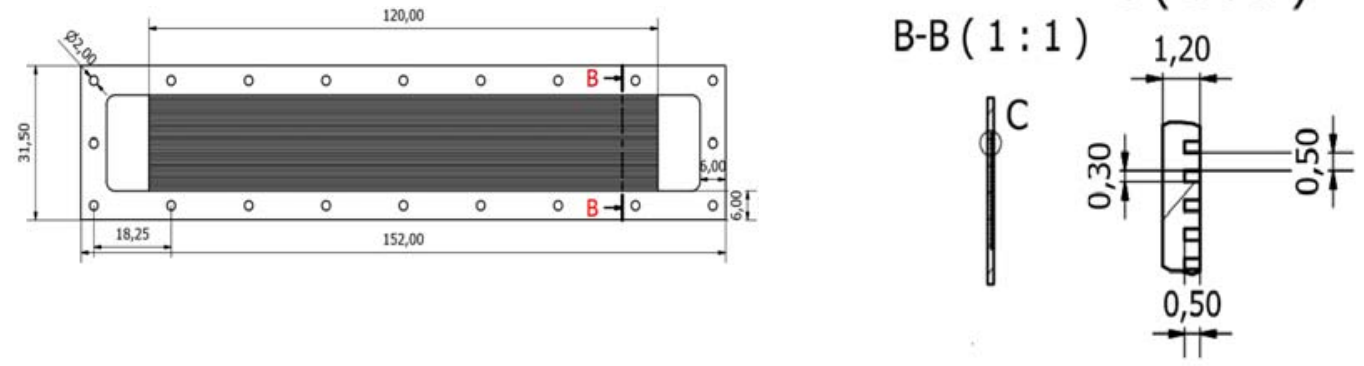

Figure 2. Dimensions of a microchannel heat sink

Table 1. Summary of microchannel dimensions for a different cross section

\begin{tabular}{llll}
\hline Cross section of microchannel & $\mathrm{W}(\mathrm{mm})$ & $\mathrm{H}(\mathrm{mm})$ & $\mathrm{R}(\mathrm{mm})$ \\
\hline Rectangle & 0.3 & 0.5 & \\
Rounded edge rectangle & & 0.07 & 0.25 \\
\hline
\end{tabular}




\subsection{Numerical Simulation}

For the numerical simulation experiment the conjugated 3D flow and the heat transfer models of the COMSOL software package were employed to analyse the flow and heat transfer characteristics of the test sample. To simplify the analytic process assumptions for the model were as follows:

(1) Flow was a two phase flow and was incompressible.

(2) Thermo physical properties of fluids and solids were assumed to be unaffected by temperature.

(3) Gravitational forces are neglected and there is no internal heat generation within the model.

(4) The walls of the channel have a no-slip condition for velocity and temperature.

The governing equations describing the microchannel heat sink consist of the continuity equation (1), momentum equations ( $2 \mathrm{a}, 2 \mathrm{~b}, 2 \mathrm{c})$, energy equation (3) and $\mathrm{k}-\boldsymbol{\varepsilon}$ equations. The mathematical model in 3D Cartesian coordinates is indicated as follows:

$$
\begin{gathered}
\frac{\partial \rho}{\partial \mathrm{t}}+u \frac{\partial \rho}{\partial x}+v \frac{\partial \rho}{\partial y}+w \frac{\partial \rho}{\partial z}+\rho\left[\frac{\partial u}{\partial x}+v \frac{\partial v}{\partial y}+w \frac{\partial w}{\partial z}\right]=0 \\
\frac{\partial u}{\partial \mathrm{t}}+u \frac{\partial u}{\partial x}+v \frac{\partial u}{\partial y}+w \frac{\partial u}{\partial z}=-\frac{1}{\rho} \frac{\partial \rho}{\partial x}+\frac{\mu}{\rho}\left(\frac{\partial^{2} u}{\partial x^{2}}+\frac{\partial^{2} u}{\partial y^{2}}+\frac{\partial^{2} u}{\partial z^{2}}\right) \\
\frac{\partial u}{\partial \mathrm{t}}+u \frac{\partial v}{\partial x}+v \frac{\partial v}{\partial y}+w \frac{\partial v}{\partial z}=-\frac{1}{\rho} \frac{\partial \rho}{\partial x}+\frac{\mu}{\rho}\left(\frac{\partial^{2} v}{\partial x^{2}}+\frac{\partial^{2} v}{\partial y^{2}}+\frac{\partial^{2} v}{\partial z^{2}}\right) \\
\frac{\partial w}{\partial \mathrm{t}}+u \frac{\partial w}{\partial x}+v \frac{\partial w}{\partial y}+w \frac{\partial w}{\partial z}=-\frac{1}{\rho} \frac{\partial \rho}{\partial x}+\frac{\mu}{\rho}\left(\frac{\partial^{2} w}{\partial x^{2}}+\frac{\partial^{2} w}{\partial y^{2}}+\frac{\partial^{2} w}{\partial z^{2}}\right) \\
\frac{\partial T}{\partial t}+u \frac{\partial T}{\partial x}+v \frac{\partial T}{\partial y}+w \frac{\partial T}{\partial z}=-\frac{\lambda}{\rho C_{P}}\left(\frac{\partial^{2} T}{\partial x^{2}}+\frac{\partial^{2} T}{\partial y^{2}}+\frac{\partial^{2} T}{\partial z^{2}}\right)+Q_{i} \\
\rho \frac{\partial u}{\partial t}+\rho(u . \nabla) u=\nabla \cdot\left[-p l+\left(\mu+\mu_{T}\right)\left(\nabla u+(\nabla u)^{T}\right)-\frac{2}{3}\left(\mu+\mu_{T}\right)(\nabla \cdot u) l-\frac{2}{3} \rho k l\right]+F \\
C_{p}=\frac{1}{\rho}\left(\theta_{\rho p h a s e 1} C_{\rho p h a s e 1}+(1-\theta)_{\rho p h a s e 2} C_{\rho p h a s e 2}\right)+L \frac{\delta \alpha_{m}}{\delta T}
\end{gathered}
$$

where $\mathrm{T}$ is temperature, $t$ is time, $C_{p}$ is specific heat at constant pressure, $\rho$ is density, $\mu_{T}$ is dynamic viscosity, $k$ is thermal conductivity and turbulent kinetic energy, $Q_{i}$ is internal heat generation, $u$ is velocity, $p$ is pressure, $\varepsilon$ is rate of viscous dissipation.

\section{$2.3 \quad$ Experimental Setup}

The schematic diagram of the test loop is shown in Fig. 3. The accuracy of instruments is listed in Table 2. Some devices were used for experimental setup.

1. Temperature sensors: T - types

2. Pumps: PU-2087, manufactured by Jasco

3. Heater: AXW-8, manufactured by Medilab

4. Pressure sensor: PMP4110, manufactured by Duck

5. Electric balance: TE-214S, manufactured by Sartorious. 


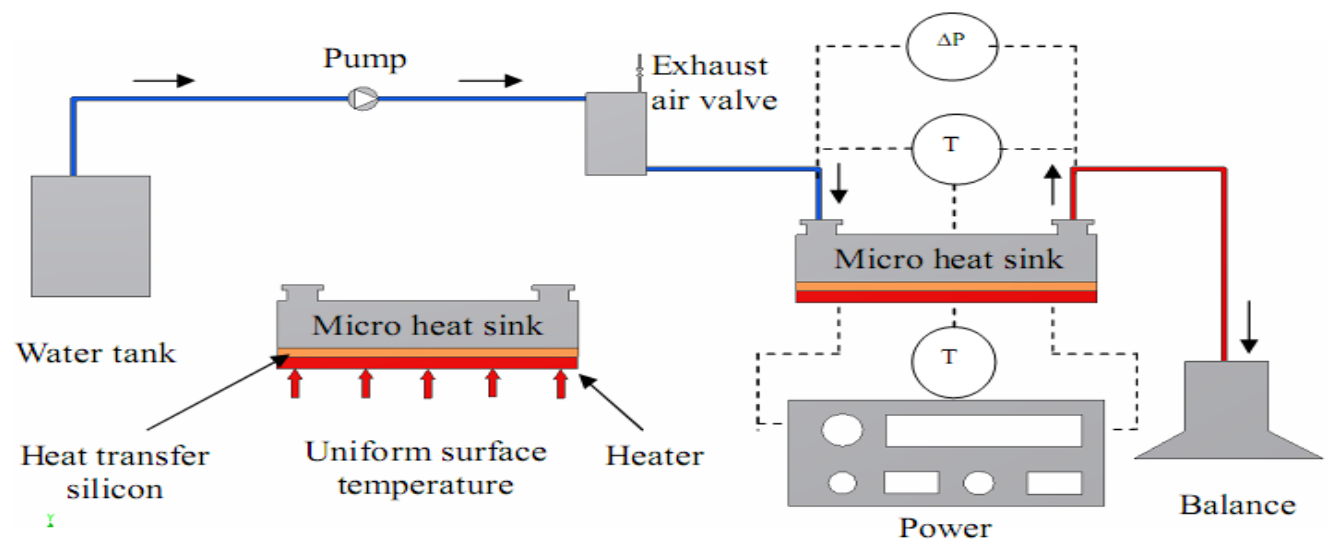

Figure 3. Schematic diagram of the test loop

Table 2. Accuracy of instruments

\begin{tabular}{ll}
\hline Parameters & Tolerance \\
\hline Temperature & $\pm 0,1^{\circ} \mathrm{C}$ \\
Pressure & $\pm 0,025 \% \mathrm{FS}$ \\
Mass flow rate & $\pm 0,0015 \mathrm{~g}$ \\
Channel depth & $\pm 7 \mu \mathrm{m}$ \\
Channel width & $\pm 10 \mu \mathrm{m}$ \\
Channel length & $\pm 70 \mu \mathrm{m}$ \\
\hline
\end{tabular}

\section{Results and Discussion}

For the numerical simulation and experimental data all working conditions were kept the same except the cross sectional area of microchannels. Table 3 shows the general parameters for the numerical simulation and experimental data. Fig. 4 shows the location of a full phase transition between phase 1 (liquid) and phase 2 (vapour) in terms of vapour quality and output temperature in rectangular microchannels by the numerical method. It is observed that the phase transition curve is in a parabolic shape. It is due to the heat being dissipated at marginal channels to the outside of the substrate. Therefore the phase transition of middle channels was faster than that obtained from the marginal channels. The results showed that the maximum exit quality gained at the end of channels xe $=0.9896$ and the maximum outlet temperature of $99.701^{\circ} \mathrm{C}$. Fig. 5 shows the nucleation site of phase transition where the bubble nucleates and departs from the nucleation site. It is observed that the first bubble nucleate is at the time of $18 \mathrm{~s}$, as shown in Fig.6.

Table 3. General parameters

\begin{tabular}{l}
\hline Fixed parameters \\
\hline Heat power: Psource $=132 \mathrm{~W}$ \\
Inlet temperature of water: Tin $=60{ }^{\circ} \mathrm{C}$ \\
Ambient temperature: Tamb $=30{ }^{\circ} \mathrm{C}$ \\
Source temperature: $\mathrm{TS}=120{ }^{\circ} \mathrm{C}$ \\
Mass flow rate: $\mathrm{G}=0.3 \mathrm{~g} / \mathrm{s}$ \\
Cross section area: $\mathrm{A}=0.15 \mathrm{~mm}^{2}$ \\
\hline
\end{tabular}




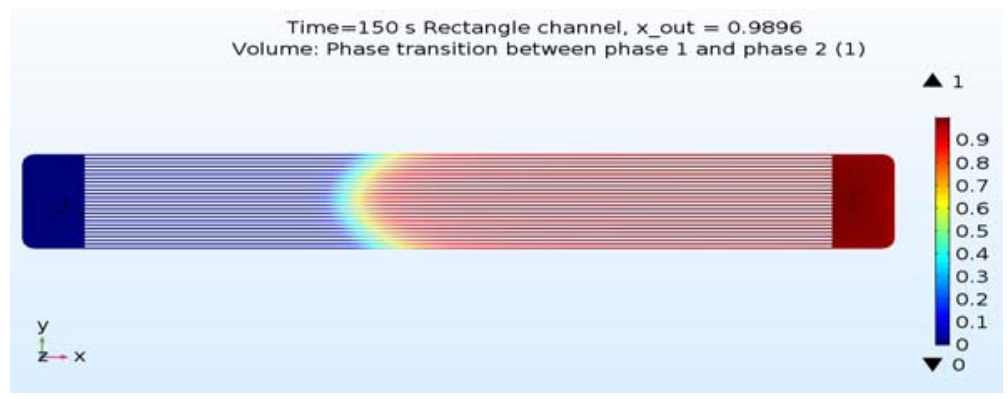

(a) The vapour quality (for the heating side)

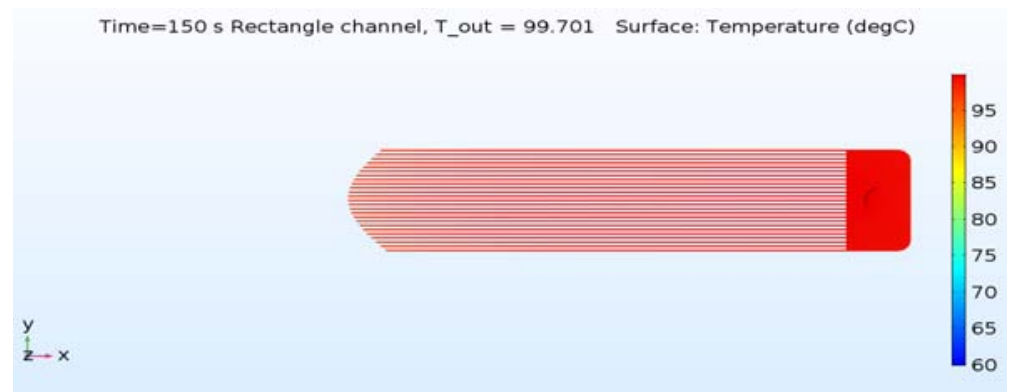

(b) The temperature profile of vapour (for the heating side)

Figure 4. The location of full phase transition in rectangular microchannels

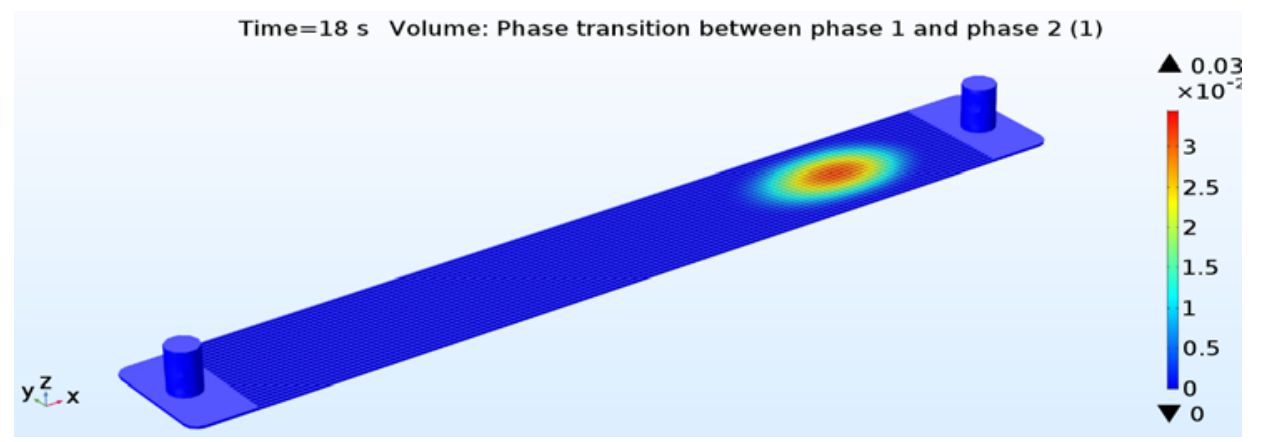

Figure 5. The nucleation site of the phase transition in rectangular microchannels

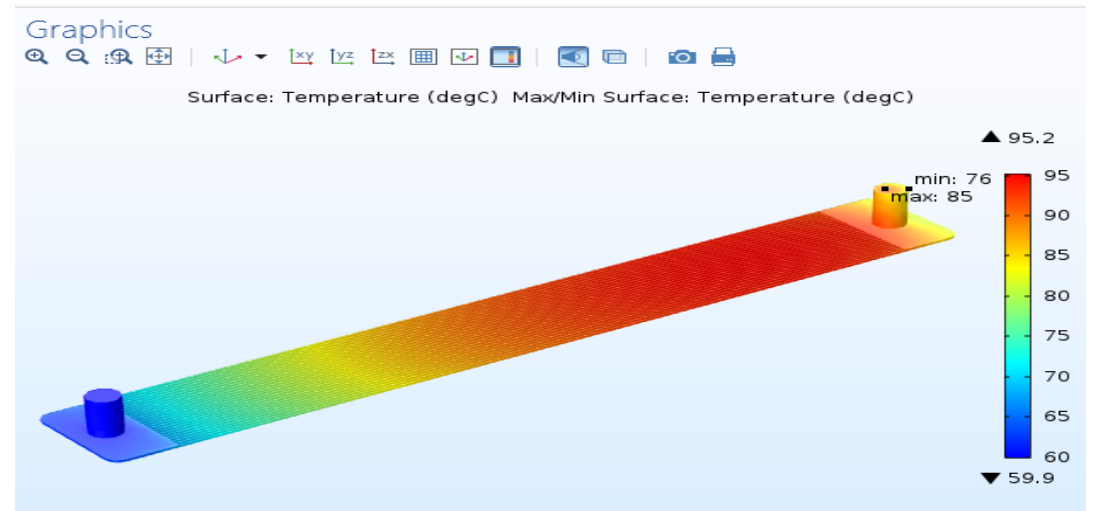

Figure 6. The maximum output temperature with the first bubble nucleate in rectangular microchannels 
Point Graph: Temperature (degC)

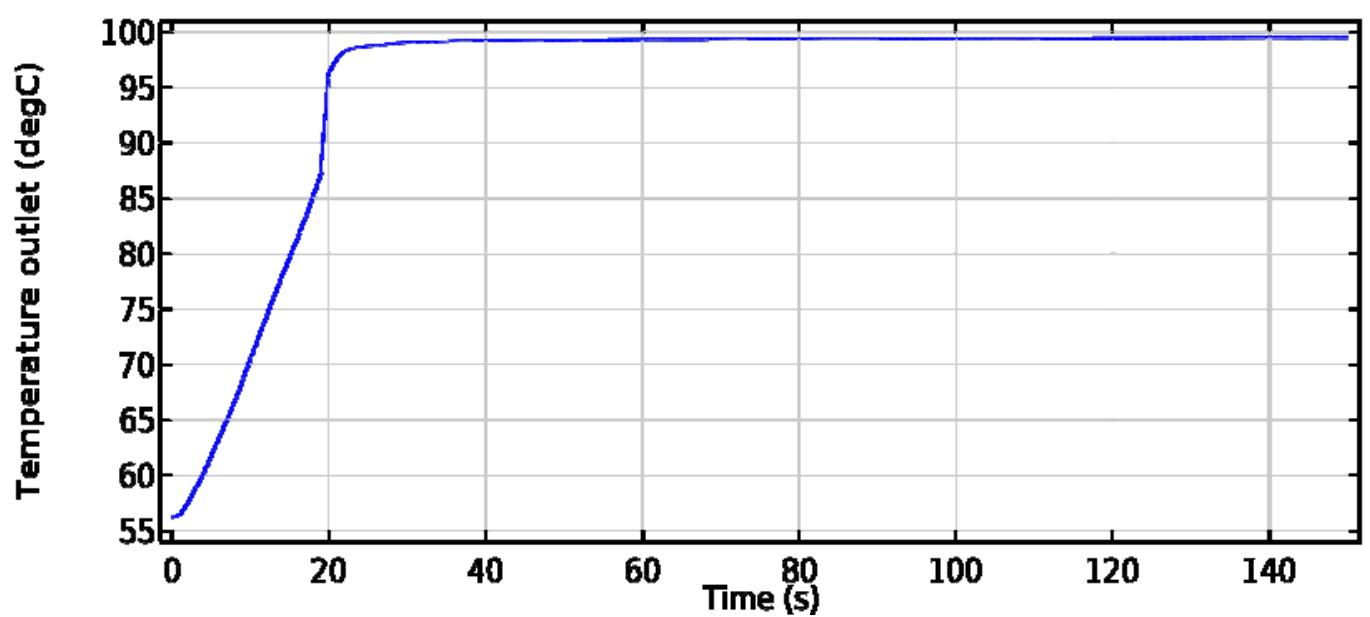

Figure 7. The outlet temperature of vapour vs. time by the numerical method

The outlet temperature of vapour in the rectangular microchannel heat sink is shown in Fig. 7. It is noted that the output vapour temperature achieved a steady state with the maximum time at 2 minutes, 30 seconds. It is matched with the phase transition location, as shown in Fig.4.

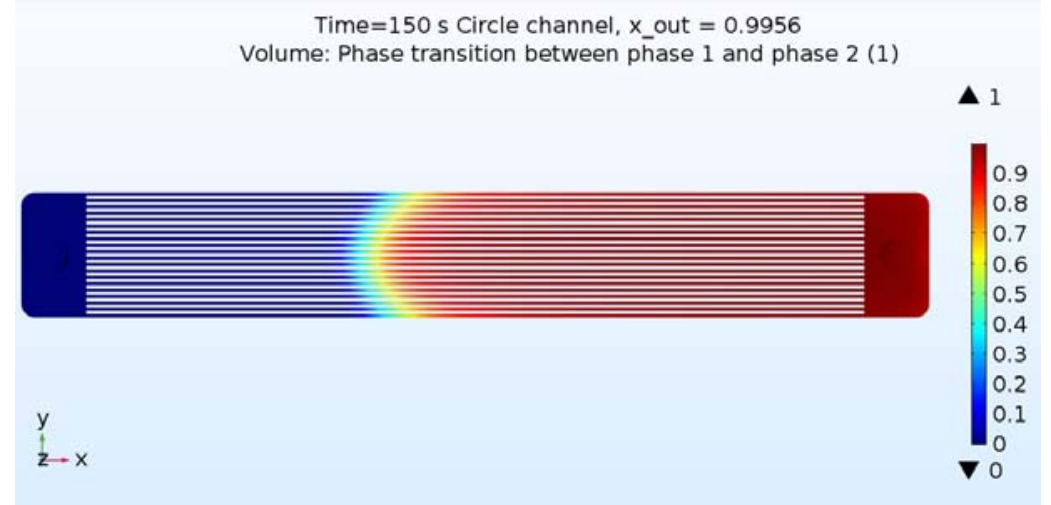

(a) The vapour quality (for the heating side)

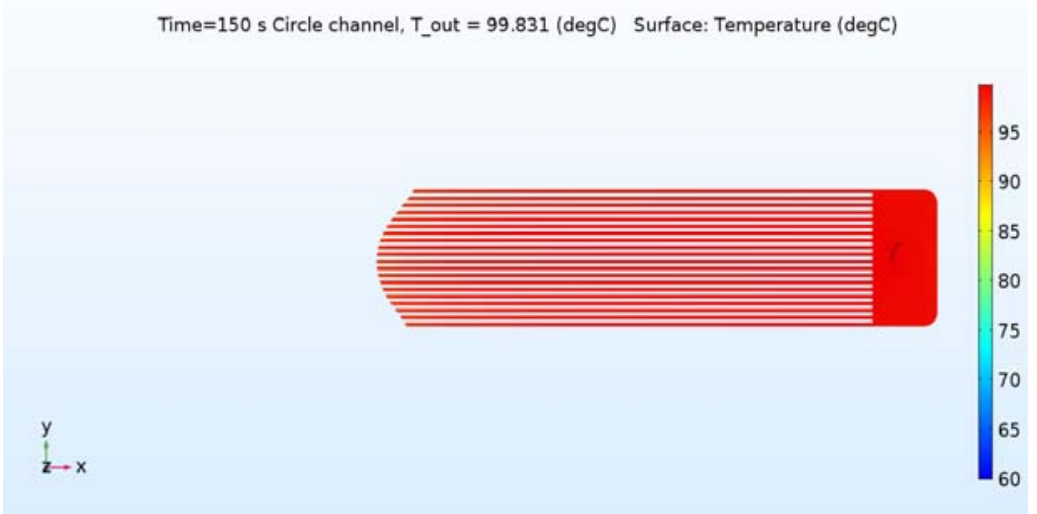

(b) Temperature profile of vapour (for the heating side)

Figure 8. The location of a full phase transition in rounded edge rectangular microchannels 


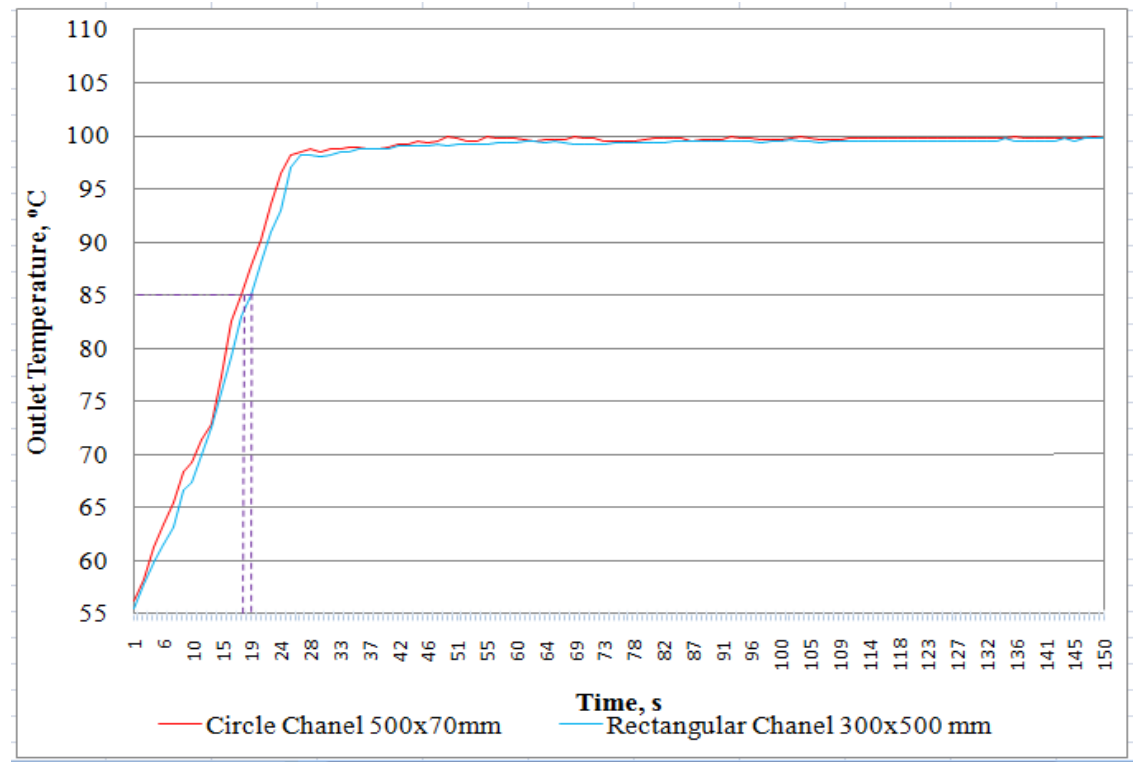

Figure 9. A numerical comparison between the rectangular and rounded edge rectangular microchannels

Fig. 8 shows the location of a full phase transition between phase 1 and phase 2 in terms of vapour quality and output temperature in rounded edge rectangular microchannels by numerical simulation. The results showed that the maximum vapour quality gained at the end of channels xe $=0.9956$ and the maximum outlet temperature was 99.831 oC. It is observed that both the outlet temperature and vapour quality of the rounded edge rectangular microchannel heat sink is higher than that obtained from the rectangular microchannel heat sink as shown in Fig. 9. Fig. 9 shows that the time for the nucleation site in the rounded edge rectangular microchannel heat sink is earlier than the rectangular one by about 1.5s. This is in clear alignment with the data from experiments performed as shown in Fig. 10. Figs. 9 and 10 indicate that the numerical results are quite agreeable with the experimental data.

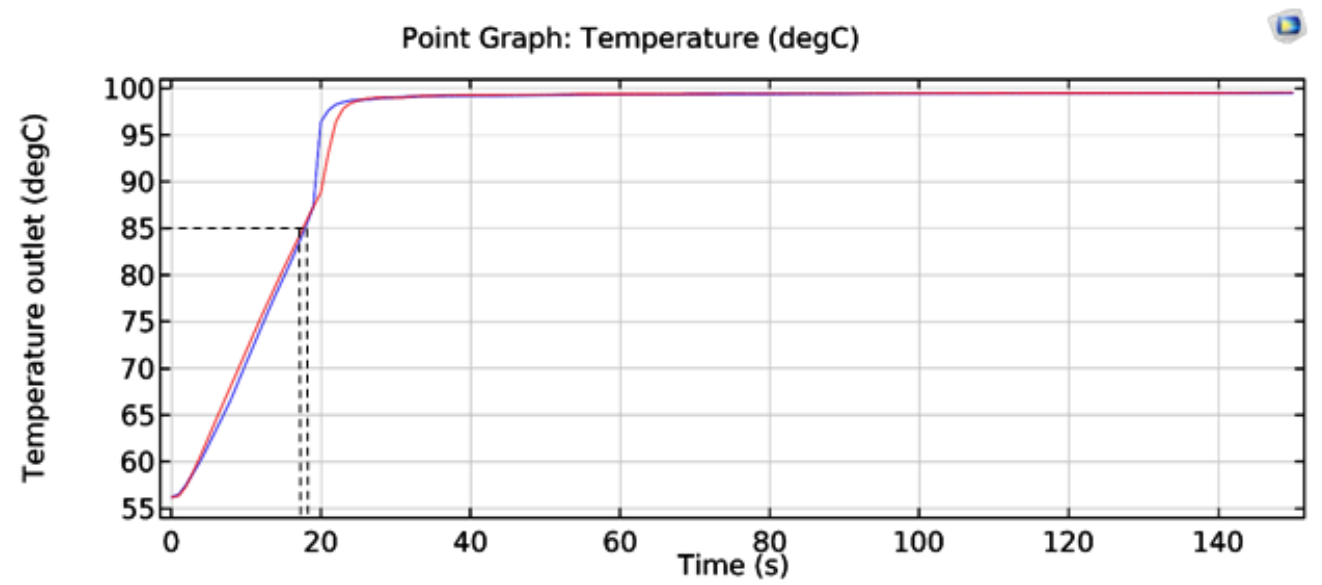

Figure 10. An experimental comparison on outlet temperatures of the two heat sinks

It is noted that the numerical simulations from Figs. 4-9 are new results for entire models (consisting of the inlet/outlet holes, manifolds, and microchannels) and the two phase flow. The results have not yet been seen in literature reviews. It is important for further studies to be carried out on evaporation in microchannels.

\section{Conclusion}


The numerical simulation and experimental data of two microchannel heat sinks with different cross section areas of channels have been done in order to find out the effects of microchannel geometry on the phase transition for the two phase flow.

The study indicated that the rounded edge rectangular microchannel heat sink has its phase transition earlier than the rectangular one in both numerical simulation and experiments by about 1.5 seconds. Besides, the outlet temperature and vapour quality of rounded edge rectangular microchannel heat sinks are higher than those obtained from the rectangular microchannel heat sink.

The phase transition curves achieved in the evaporation are parabolic in shape. The output vapour temperature achieved a steady rate with a maximum time at around 2 minutes, 30 seconds.

In addition the numerical results are quite consistent with the experimental data. These numerical results are yet to be seen in literature reviews. It's vitally important that further studies on evaporation in microchannels be performed.

\section{Acknowledgments}

Support for this work comes from the following projects: Project No. T2018-TĐ which is sponsored by specific research fields at HCMUTE and Project No. B2015.22.01 which is sponsored by specific research fields from the Ministry of Education and Training, Vietnam. Their support is deeply appreciated.

\section{References}

1. R. Yun, J.H. Heo and Y.C. Kim, "Evaporative heat transfer and pressure drop of R410A in microchannels," International Journal of Refrigeration, Vol. 29, pp. 92-100, 2006.

2 B. Schilder, S. Y. C. Man, N. Kasagi, S. Hardt and P. Stephan, "Flow Visualization and Local Measurement of Forced Convection Heat Transfer in a microtube," Journal of Heat Transfer, Vol. 132, 2010

3. N. R. Kuppusamy, R. Saidur, N.N.N. Ghazali and H.A.Mohammed, "Numerical study of thermal enhancement in microchannel heat sink with secondary flow," International Journal of Heat and Mass Transfer, Vol. 78, pp. 216223, 2014 .

4. O. Barlay Ergu, O.N. Sara, S. Yapıcı and M.E. Arzutug, "Pressure drop and point mass transfer in a rectangular microchannel," International Communications in Heat and Mass Transfer, Vol. 36, pp. 618-623, 2009.

5. S.G. Singh, A. Kulkarni, S.P. Duttagupta, B.P. Puranik, A.Agrawal, "Impact of aspect ratio on flow boiling of water in rectangular microchannels," Experimental Thermal and Fluid Science, Vol. 33, pp. 153-160, 2008.

6. Serizawa, A., Feng, Z., Kawara, Z., "Two-phase flow in Microchannels," Experimental Thermal and Fluid Science, Vol. 26, pp.703-714, 2002

7. A. Megahed, "Experimental investigation flow boiling characteristics in a cross linked microchannel heat sink," International Journal of Multiphase Flow, Vol. 37, pp. 380-393, 2011.

8. Jaeseon Lee, Issam Mudawar, "Two-phase flow in high-heat-flux microchannel heat sink for refrigeration cooling applications: Part I-pressure drop characteristics," International Journal of Heat and Mass Transfer, Vol. 48, pp. 928-940, 2005.

9. Guodong Wang, Ping Cheng, A.E. Bergles, "Effects of inlet/outlet configurations on flow boiling instability in parallel microchannels," International Journal of Heat and Mass Transfer, Vol. 51, pp. 2267-2281, 2008.

10. A. Megahed, I. Hassan, "Two-phase pressure drop and flow visualization of FC-72 in a silicon microchannel heat sink," Int. J. Heat Fluid Flow, Vol. 30, pp. 1171-1182, 2009.

11. Sui, Y. Sui, C.J. Teo, P.S. Lee, Y.T. Chew, C. Shu, "Fluid flow and heat transfer in wavy microchannels," International Journal of Heat and Mass Transfer, Vol. 53, pp. 2760-2772, 2010.

12. T. Tsukamoto and R. Imai, "Thermal characteristics of a high heat flux micro evaporator," Experimental Thermal and Fluid Science, Vol. 30, pp. 837-842, 2006. 